\title{
O PAPEL DO QUADRO COMUM EUROPEU DE REFERÊNCIA PARA IDIOMAS: APRENDIZAGEM, ENSINO E AVALIAÇÃO (QCER) NA INTERNACIONALIZAÇÃO DAS IES: UMA ANÁLISE SOB A PERSPECTIVA DO LETRAMENTO CRÍTICO E DOS MULTILETRAMENTOS
}

\section{THE ROLE OF THE COMMON EUROPEAN FRAMEWORK OF REFERENCE FOR LANGUAGES: LEARNING, TEACHING AND EVALUATION (CEFR) IN THE INTERNATIONALIZATION OF HEIS: AN ANALYSIS FROM THE PERSPECTIVE OF CRITICAL LITERACY AND MULTILITERACIES}

\section{Josiane Brunetti Cani ${ }^{*}$ Maria Elizabete Vilella Santiago **}

\section{RESUMO}

Este trabalho objetiva investigar de que forma os descritores do Quadro Comum Europeu de Referência para Idiomas: Aprendizagem, Ensino e Avaliação (QCER) se comportam diante das demandas de uma sociedade cuja comunicação é cada vez mais, multimodal, digital e global. Para alcançar tal objetivo, o artigo aborda estudos sobre Multiletramentos e Letramento Crítico, no intuito de embasar a discussão sobre os descritores referentes aos níveis $\mathrm{C} 1$ e $\mathrm{C} 2$, pois, para interações eficientes em uma sociedade cada vez mais digital e globalizada, é necessário que utilizadores proficientes possuam, e saibam usar, uma gama considerável de recursos semióticos. A metodologia qualitativa, abrangendo aspectos da concepção do QCER, sua abordagem comunicativa e os descritores de produção e compreensão oral e escrita, foi utilizada. A análise permitiu concluir que a da aplicabilidade do QCER no programa de internacionalização do Ensino Superior requer algumas ações específicas que permitiriam atualizar seus descritores, de forma a atender às práticas dos multiletramentos, do letramento crítico e das tecnologias digitais.

Palavras-chave: QCER multiletramentos; letramento crítico.

\footnotetext{
* Universidade Federal de Minas Gerais, Belo Horizonte (MG), Brasil. josicani@gmail.com

** Universidade Federal de Minas Gerais, Belo Horizonte (MG), Brasil. elizabetesantiago.unifei@ gmail.com
} 


\section{ABSTRACT}

This work aims at investigating how the guidelines of the Common European Framework of Reference for Languages: Learning, Teaching, Assessment (CEFR) behave in face of the demands of a society whose communication is increasingly multimodal, digital and global. To achieve such a goal the article examines studies on Multiliteracies and Critical Literacy for grounding the discussion of the descriptors referring to levels $\mathrm{C} 1$ and $\mathrm{C} 2$, since it is expected that proficient users have, and can use, a considerable range of semiotic resources to efficiently interact in a digital and globalized society. We used a qualitative methodology covering aspects of CEFR design, its communicative approach and the guidelines of oral and written production and comprehension. The analysis led to the conclusion that the influence of the CEFR in the program of internationalization of Higher Education demands some specific actions which would allow for the updating of its guidelines, so as to meet with the multiliteracies, critical literacy and digital technologies social practices.

Keywords: CEFR; multiliteracies; critical literacy.

\section{INTRODUÇÃO}

O advento da era digital, representado pela criação e expansão da Internet, acelerou, exponencialmente, o processo de globalização iniciado com as explorações de outros continentes pelas potências da Europa, nos séculos XV e XVI. Como consequência, barreiras geográficas foram rompidas, possibilitando o acesso a diferentes culturas e contextos sociais, além de promover o estreitamento nas relações pessoais, acadêmicas, profissionais, econômicas e até mesmo governamentais, entre países e continentes. Nesse contexto, o conhecimento assumiu a condição de bem compartilhado e construído de forma conjunta.

A expansão das novas tecnologias, segundo Lévy (2011), trouxe a oportunidade de uma desterritorialização que permitiu estarmos, ao mesmo tempo, aqui e lá, tornando-nos nômades de novos costumes, ao migrarmos de um espaço a outro, e levando-nos à (des)conexão para a abertura de novos espaços. Dessa forma, a interação dos cidadãos provindos de diferentes contextos culturais para práticas sociais que visem à construção do conhecimento requer habilidades que atendam às demandas de uma sociedade global.

Atendendo a essas exigências, o processo de internacionalização das Instituições de Ensino Superior (IES) veio como uma resposta natural às necessidades dessa era globalizada. Assim, além de intercâmbios em nível de graduação, pósgraduação e pesquisa, fomentados por órgãos oficiais do governo, programas de ensino de idiomas dentro das universidades têm sido implementados não somente para capacitar os futuros intercambistas, mas, também, preparar as instituições para receber discentes, docentes e pesquisadores internacionais. Os resultados obtidos nos programas são mensurados por exames de proficiência no idioma alvo que, por 
sua vez, seguem diretrizes do Quadro Comum Europeu de Referência para Idiomas: Aprendizagem, Ensino e Avaliação (QCER) ${ }^{1}$, publicado em 2001.

O site do Conselho da Europa aponta, com bases empíricas e consultas generalizadas, que o QCER possibilita

$\Rightarrow$ promover o plurilinguismo e a diversificação na escolha das línguas no currículo;

$\Rightarrow$ apoiar o desenvolvimento e a demonstração do perfil plurilíngue de alunos individuais;

$\Rightarrow$ desenvolver e rever o conteúdo dos currículos de línguas e definir descritores positivos adaptados à idade, aos interesses e às necessidades dos alunos;

$\Rightarrow$ conceber e desenvolver livros didáticos e material didático;

$\Rightarrow$ apoiar a formação de professores e a cooperação entre professores de diferentes idiomas;

$\Rightarrow$ melhorar a qualidade e o sucesso na aprendizagem, ensino e avaliação; e

$\Rightarrow$ facilitar a transparência nos testes e a comparabilidade das certificações (CONSELHO DA EUROPA, 2017).

No entanto, o QCER foi planejado e discutido ainda no início da era digital e, portanto, anteriormente à grande transformação das interações e das tecnologias da comunicação vivenciada na última década. Assim, mesmo com o avanço da proposta em padronizar os níveis de conhecimento da língua nas quatro habilidades de ouvir, ler, falar e escrever, é preciso alinhar suas práticas contemporâneas às tecnologias digitais. Nesta discussão, pretendemos abordar as lacunas existentes no letramento multimodal, cada vez mais necessário nas interações deste século, bem como a análise crítica dos discursos, identidades, ideologias, interesses e relações de poder. A partir dos hiatos identificados, propomos reflexões complementares que contemplam as habilidades comunicativas em ambientes multimodais e digitais que favoreçam a inserção de um viés crítico nas atividades de ensino/aprendizagem e avaliação. Nossa proposta justifica-se pela importância de (multi)letrar os cidadãos para agirem como protagonistas em uma sociedade permeada pelo surgimento de novos recursos semióticos, devido às inovações tecnológicas e ao subsequente rompimento das barreiras geográficas e temporais.

1. Tradução nossa para: "Common European Framework of Reference for Languages: Learning, Teaching, Assessment" (CEFR). 


\section{O QCER NO PROCESSO DE INTERNACIONALIZAÇÃO DAS IES}

O QCER é resultado de um trabalho iniciado em 1991 por representantes da União Europeia com a participação de membros do Canadá e dos Estados Unidos. Sua última publicação data de 2001 e fornece uma base comum para a elaboração de material didático, programas de cursos de idiomas e exames de proficiência, por meio de descritores, denominados utilizadores no documento, que medem e avaliam o nível de proficiência dos aprendizes. Além de elementos linguísticos, as habilidades descritas no QCER incluem aspectos culturais relacionados aos idiomas (CONSELHO DA EUROPA, 2001).

As habilidades são divididas em seis níveis de proficiência que vão do iniciante até o fluente (Figura 1) e guiam a classificação das competências dos aprendizes/ utilizadores em provas de nivelamento de escolas de idiomas, processos de seleção para programas de intercâmbio e cursos de pós-graduação, entre outros.

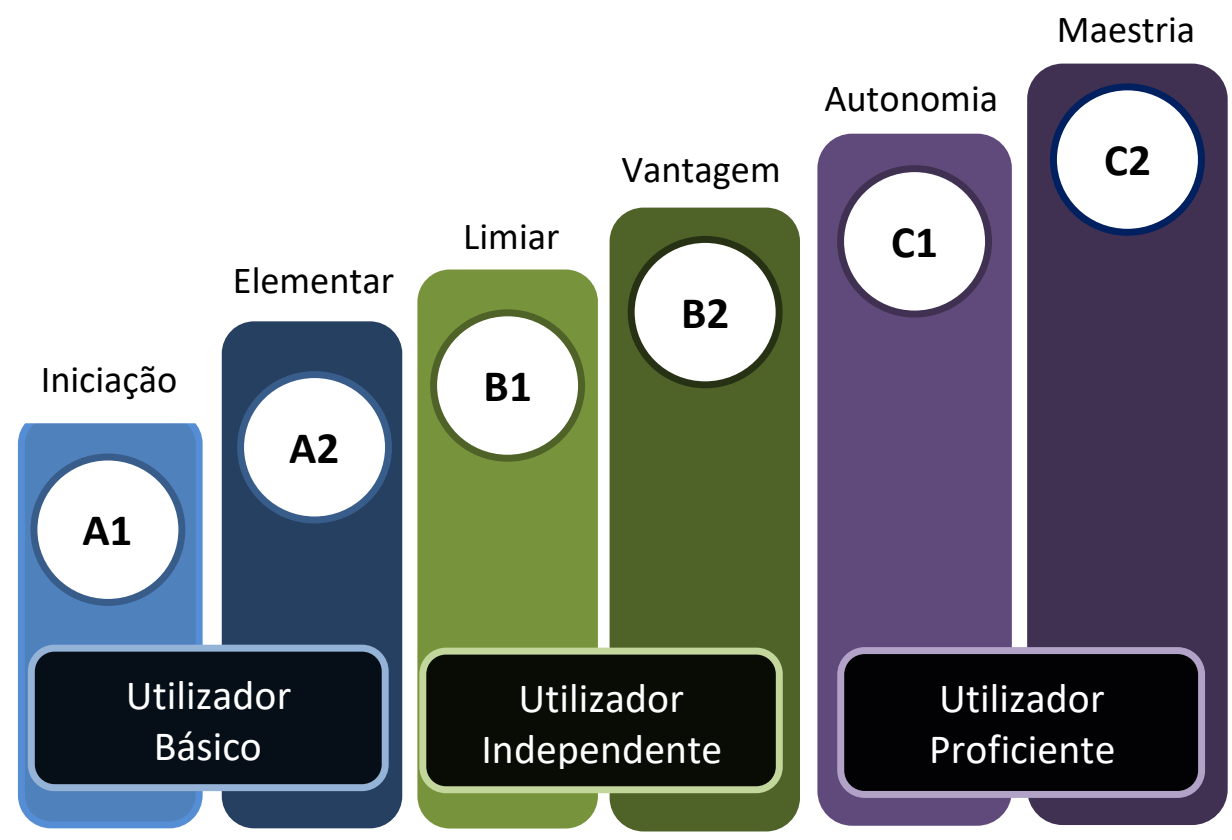

Figura 1. Níveis de proficiência de acordo com o QCRE

Fonte: Conselho da Europa (2001).

O QCER tem sido adotado no programa de internacionalização das IES no Brasil, o que ocorre, principalmente, por meio de programas do Governo Federal: 
a) Ciência sem Fronteiras (CSF), que promoveu a mobilidade estudantil entre os anos de 2012 e 2016, e b) Idiomas sem Fronteiras (ISF), para preparar os futuros intercambistas e possibilitar a recepção de professores e alunos de outros países, oferecendo, gratuitamente, testes de proficiência, cursos presenciais e online (BRASIL, 2011). O ISF, que inicialmente se restringia à Língua Inglesa (LI), já iniciou o programa para ensino do Francês e do Espanhol e, em 2017, abriu editais em um número reduzido de IES para Italiano, Alemão e Japonês (IDIOMAS SEM FRONTEIRAS, 2017).

Atualmente, para o inglês, o programa oferece o exame de proficiência TOEFL ITP que, além de ter sido aceito por alguns países participantes do CSF, tem substituído as provas de inglês de alguns cursos de pós-graduação stricto sensu. Nem todos os países com programa de intercâmbio, contudo, aceitam o TOEFL ITP por este não conter as seções de speaking e writing, preferindo a versão completa, o TOEFL IBT, não oferecido gratuitamente (EDUCATIONAL TESTING SERVICE, 2015). Outro exame de proficiência em LI pago, amplamente aceito por países parceiros do CSF e em outros programas de mobilidade acadêmica, é o International English Language Testing System (IELTS).

Como a LI é a língua estrangeira (LE) dominante e com mais destaque nos programas de ensino de idiomas, avaliação e intercâmbio, é compreensível a existência de mais exames de proficiência para ela. Contudo, por ser o programa de internacionalização das IES um dos motivadores deste artigo, é relevante incluir na lista de testes de proficiência o DEFL/DALF para o francês, o DELE para o espanhol, o OnDaf para o alemão e o CILS para o italiano. O Quadro 1, a seguir, apresenta um comparativo da pontuação dos exames baseados no QCER.

Quadro 1. Comparativo dos exames de proficiência em relação ao QCER.

\begin{tabular}{|c|c|c|c|c|c|c|c|}
\hline QCER & $\begin{array}{c}\text { TOEFL } \\
\text { ITP }\end{array}$ & $\begin{array}{c}\text { TOEFL } \\
\text { IBT }\end{array}$ & IETLS & Francês & Espanhol & Italiano & OnDaf \\
\hline C2 & $\ldots$ & $\ldots$ & $8,8-9$ & DALF & DELE C2 & CILS quatro & $\ldots$ \\
\hline C1 & $627-677$ & $110-120$ & $7-8$ & DALF & DELE C1 & CILS ter & $140-145$ \\
\hline B2 & $543-626$ & $87-109$ & $5-6,5$ & DELF & DELE B2 & CILS due & $100-115$ \\
\hline B1 & $460-542$ & $57-86$ & $4-4,5$ & DELF & DELE B1 & CILS uno & $75-80$ \\
\hline A2 & $337-459$ & $\ldots$ & $\ldots$ & DELF & DELE A2 & CILS A2 & $45-50$ \\
\hline A1 & $\ldots$ & $\ldots$ & $\ldots$ & DELF & DELE A1 & CILS A1 & $\ldots . .-$ \\
\hline
\end{tabular}

Fonte: Baseado em pesquisas nas páginas oficiais de cada exame de proficiência citado.

Ao enquadrar os distintos exames de proficiência em diferentes idiomas, o QCER tenta estabelecer vínculos de cooperação entre instituições de ensino 
internacionais, por meio de uma base sólida de referência de habilidades linguísticas (CONSELHO DA EUROPA, 2001). Considerando a ampla influência das diretrizes do QCER em práticas socialmente aceitas e legitimadas, como os exames de proficiência citados e seus respectivos cursos preparatórios, que atuam como portões de acesso a outros contextos, vale questionar se o que é ensinado e avaliado é relevante para a internacionalização das IES. Para responder a esta questão, serão discutidos aspectos das teorias dos Multiletramentos e do Letramento Crítico, alicerces para a análise do QCER a que este artigo se propõe.

\section{DA ALFABETIZAÇÃO AO MULTILETRAMENTO E AO LETRAMENTO CRÍTICO}

A evolução da linguagem oral para a escrita, como toda mudança de tecnologia, favoreceu determinadas classes sociais. O acesso a esse tipo de linguagem, antes restrito a uma elite minoritária, passa a ser 'democratizado' com a educação compulsória. Contudo, as práticas de letramento baseadas na automatização do alfabeto e na memorização e reprodução de normas gramaticais (SOARES, 2009) perpetuam a exclusão dos menos favorecidos. A este tipo de práxis, vertical e antidialógica, que posiciona os educadores como narradores de seus conhecimentos e os educandos como receptores passivos e acríticos de um conhecimento determinado de cima para baixo, Freire (1974) denomina educação bancária.

Essa visão distorcida permaneceu durante muito tempo, porém, a problemática da alfabetização e das altas taxas de repetência exigiu uma reflexão sobre os propósitos dos usos sociais da escrita e da leitura (FERREIRO; TEBEROSKY, 1986). No ímpeto de se buscar explicação para esse fenômeno, surge o termo letramento, como representação dessa nova condição que vá para além do domínio da leitura e da escrita, mas que, também, conforme Soares (2009, p. 65), cubra "[...] uma vasta gama de conhecimentos, habilidades, capacidades, valores, usos e funções sociais; o conceito de letramento envolve, portanto, sutilezas e complexidades difíceis de serem contempladas em uma única definição".

Definir unidirecionalmente o termo letramento é tarefa complexa, considerando sua amplitude e complexidade. Assim, muitas discussões são focadas nas habilidades de leitura e de escrita, principalmente as que ainda se mantêm isoladas do contexto social. Esse modelo de letramento, denominado autônomo por Street (1984) e funcional por Castell, Luke e MacLennan (1986), é tratado como neutro e igual para todos os contextos. 
Street (1984) problematiza o letramento autônomo, questionando sua neutralidade ideológica e política e ressaltando seu papel na disseminação de valores de uma classe social dominante, bem como na manutenção da sua hegemonia. O autor propõe, como alternativa, o modelo ideológico que considera a dimensão social com suas especificidades e complexidades, já que vê as práticas de letramento como formas de ideologia e de poder que podem manter a estrutura social ou desafiá-la. O conceito também abarca a multiplicidade de letramentos possíveis em diferentes sociedades e dentro de um mesmo grupo social. Assim, contradiz pressupostos que favoreciam alguns tipos de letramento diretamente relacionados a práticas e grupos sociais dominantes.

Soares (2009) também advoga um modelo de letramento relacionado às práticas sociais. Reconhece, porém, que, além da dimensão social, que determina e calibra as normas das interações de acordo com as variáveis do contexto, há uma dimensão individual do letramento relacionada às habilidades de leitura e de escrita. As duas dimensões se sobrepõem e mantêm uma relação bidirecional.

Atualmente, em função do contexto sociohistórico e dos elementos postos à disposição pelas tecnologias digitais, Lankshear, Snyder e Green (2000) propõem a complexidade do letramento em uma abordagem tridimensional. Nesse cenário, os autores ressaltam que, por tecnologia, deve-se entender qualquer e todo aparato utilizado na construção e na comunicação dos significados, desde as pinturas rupestres, evoluindo para a fala, a escrita primitiva, a escrita em papel, a impressão, o cinema, a Internet e a realidade virtual. Novas tecnologias em novas práticas sociais, novos contextos, demandando novos letramentos. A tecnologia per se não afeta as habilidades de letramento, mas, sim, quando inserida nas práticas sociais, favorecendo ou não certos grupos sociais.

Na relação entre linguagem e tecnologia, o letramento possui uma dimensão operacional, que se tangencia aos sistemas de estrutura interna da linguagem e ao manuseio de aparatos tecnológicos; uma dimensão cultural, que permite utilizar os sistemas para participar de forma autêntica em práticas sociais e construir significado; e uma dimensão crítica, que envolve apreciar e avaliar linguagem e recursos tecnológicos, buscando compreender as relações de poder, o contexto social, a ideologia e a seleção de elementos envolvidos. Vale ressaltar que as três dimensões ocorrem simultaneamente e de maneira intrincada.

Lankshear e Knobel (2003) discutem a necessidade de se repensar a epistemologia, mediante as influências da era digital. Segundo os autores, a relação entre o que se pode ser aprendido, o que é mais importante saber e como o conhecimento pode ser construído deve ser problematizada, diante das novas 
possibilidades de um mundo digitalizado. Assim, a epistemologia padrão "crença verdadeira justificada" e os conhecimentos declarativo e processual são desafiados em relação às mudanças nos fenômenos e nos objetos do conhecimento, na própria concepção do conhecimento e sua construção, na constituição do conhecedor e na valoração de diferentes formas do saber.

Os autores alegam, ainda, que o conhecedor tem sido definido, cada vez mais, como parte de uma comunidade que constrói o conhecimento de forma colaborativa. A ubiquidade permitida pela era digital auxilia na formação de redes ou comunidades cada vez mais heterogêneas que, por sua vez, utilizam e valorizam novos tipos de conhecimento como o interpessoal, o identitário e o multimodal (LANKSHEAR e KNOBEL, 2003). Portanto, as práticas pedagógicas devem considerar a epistemologia digital como parte integrante, de modo a transformar seus recursos em ferramentas que permitam aos aprendizes funcionar efetiva, eficiente e criticamente em seus contextos sociais.

A teoria dos Multiletramentos (NEW LONDON GROUP, 1996), em conformidade com as demandas de uma era globalizada e digital, abarca duas dimensões fundamentais: a multicultural e a multimodal. A primeira parte da negociação de discursos na construção dos significados nos múltiplos contextos culturais e sociais nos quais os cidadãos-aprendizes interagem (COPE; KALANTZIS, 2009). Tal premissa implica o reconhecimento das variantes de registro, de acordo com a situação na qual a comunicação ocorre e dependendo dos papéis sociais desempenhados pelos interlocutores, considerando, obviamente, as relações de poder. A dimensão multimodal observa utilização de uma gama de recursos para a construção do significado, a saber: o linguístico, o visual, o sonoro, o gestual e o espacial, bem como as infinitas combinações possíveis entre eles.

As práticas pedagógicas pautadas nos Multiletramentos devem perceber a (re)construção dos significados como um processo contínuo e sujeito às diferenças contextuais. Assim, em tal processo, precisam ser considerados elementos outros que vão para além da gramática, do vocabulário e da pronúncia, incorporando a multimodalidade, relacionando-os a fatores discursivos, considerando todo o contexto sociocultural. Sob essa perspectiva, surge o conceito de design, ou seja, a construção de gêneros textuais multimodais, considerando fatores socioculturais, recursos semióticos e suas potencialidades que são calibrados pelos interlocutores que se tornam designers dos significados. O processo de design é constituído de três elementos que interagem entre si de forma contínua (Figura 2). 


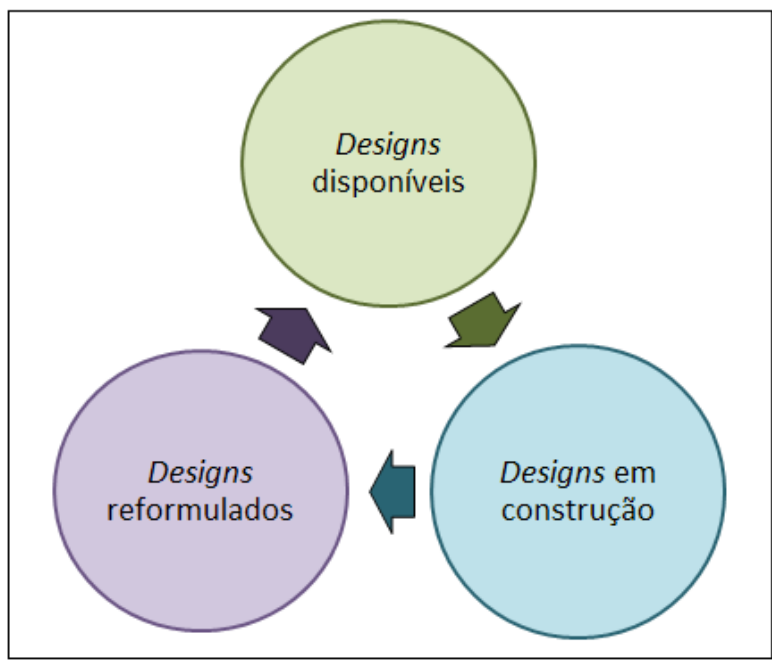

Figura 2. Processo de Design

Fonte: Adaptado de Cope; Kalantzis, 2000, 2009; Kalantzis; Cope, 2012.

Esses três elementos ressaltam o ponto de construção do significado como processo dinâmico e eficaz e não como situação conduzida por normas estáticas (NEW LONDON GROUP, 1996).

Cope e Kalantzis (2009) explicam a constituição do Design, nos três aspectos da figura anterior não como um arcabouço teórico estático direcionado à prática de ensino, mas, sim, no sentido de algo que se move constantemente, de encontro a ideias inertes de aquisição do conhecimento. Nesse contexto, os Designs disponíveis (recursos culturais e contextuais para a construção do sentido, incluindo modo, gênero e discurso), os Designs reformulados (processo de construção e recontextualização da representação do mundo por meio dos Designs disponíveis) e os Designs em construção (o mundo transformado em novos Designs disponíveis, que instanciam novos sentidos) passam a figurar em diferentes sujeitos, com visões de mundo diferenciadas e em diferentes contextos, como cenário para a imaginação e a reapropriação criativa do mundo, representando, assim, uma nova forma de aprender.

\section{O QCER SOB A PERSPECTIVA DOS MULTILETRAMENTOS E DO LETRAMENTO CRÍTICO}

Antes de discutir os conceitos embutidos nos descritores do QCER, é necessário compreender os pontos seminais de sua concepção. Logo no início 
do documento, na descrição já mencionada na seção 2 deste artigo, o QCER é definido, em termos globais, como uma base comum para os países da comunidade europeia determinarem as habilidades comunicativas esperadas em cada estágio do desenvolvimento linguístico, tornando-se um facilitador para a mobilidade dentro do continente. Esse movimento, que parte dos diferentes países para uma unificação do continente, é o que Brandt e Clinton (2002 apud MATTOS, 2014) denominam 'conexões globalizantes'. Já o caminho inverso, pelo qual comunidades locais buscam seu lugar e sua voz na sociedade globalizada, foi batizado pelos autores como 'movimentos localizantes'. Em nossas interações diárias os dois movimentos atuam em constante tensão, tentando e, por vezes, conseguindo, se equilibrar (Figura 3).

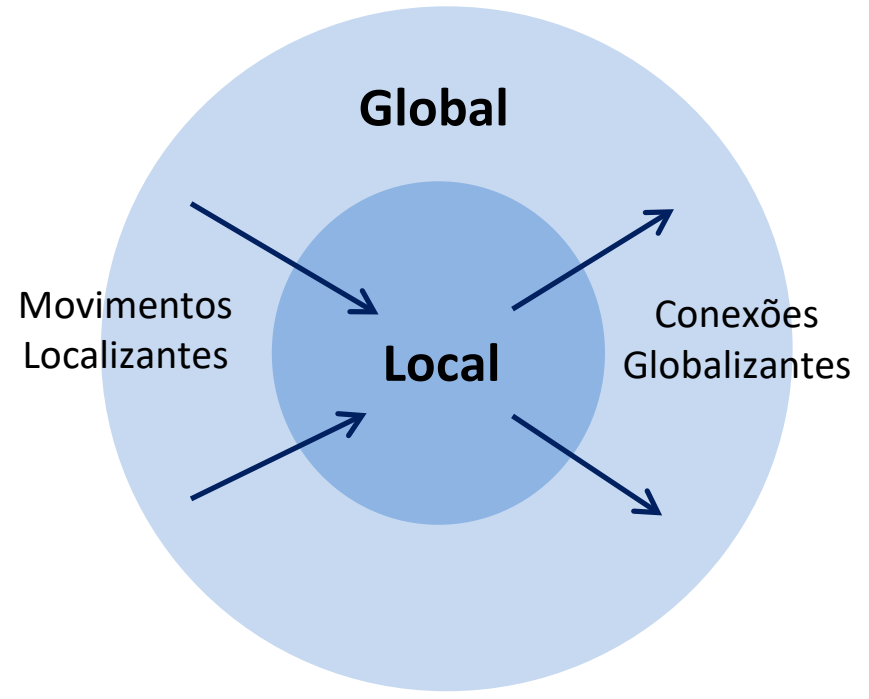

Figura 3. 0 global e o local

Fonte: Adaptado de Brandt e Clinton (2002 apud MATTOS, 2014).

Como contraponto para as diretrizes globais que objetivam padronizar os conteúdos e as avaliações de programas relacionados à aprendizagem de línguas, o QCER orienta os educadores a considerar o indivíduo e sua cultura, abrindo espaço para sua manifestação.

Como agentes sociais, todos os indivíduos estabelecem relações com um vasto conjunto de grupos sociais que se sobrepõem e que, em conjunto, definem a sua identidade. Numa abordagem intercultural, é objectivo [sic] central da educação em língua promover o desenvolvimento desejável da personalidade do aprendente no seu todo, bem como o seu sentido de identidade, em resposta à experiência enriquecedora da diferença na língua e na 
cultura. Cabe aos professores e aos próprios aprendentes reintegrar as várias partes num todo saudável e desenvolvido (CONSELHO DA EUROPA, 2001, p. 19).

Assim, o QCER adota uma abordagem plurilinguística, que permite uma interrelação de diferentes línguas e culturas como parte de uma competência linguística complexa. Essa visão vai ao encontro do ponto defendido por Canagarajah (2005 apud MATTOS, 2014) de que, para atuar plenamente em um mundo globalizado, o cidadão precisa ser capaz de transitar entre múltiplos e complexos dialetos, discursos e estratégias. A dimensão cultural, como demonstrado na análise do Quadro 2, a seguir, está, portanto, presente em parte significante dos descritores do QCER.

\section{Quadro 2. Análise do QCER}

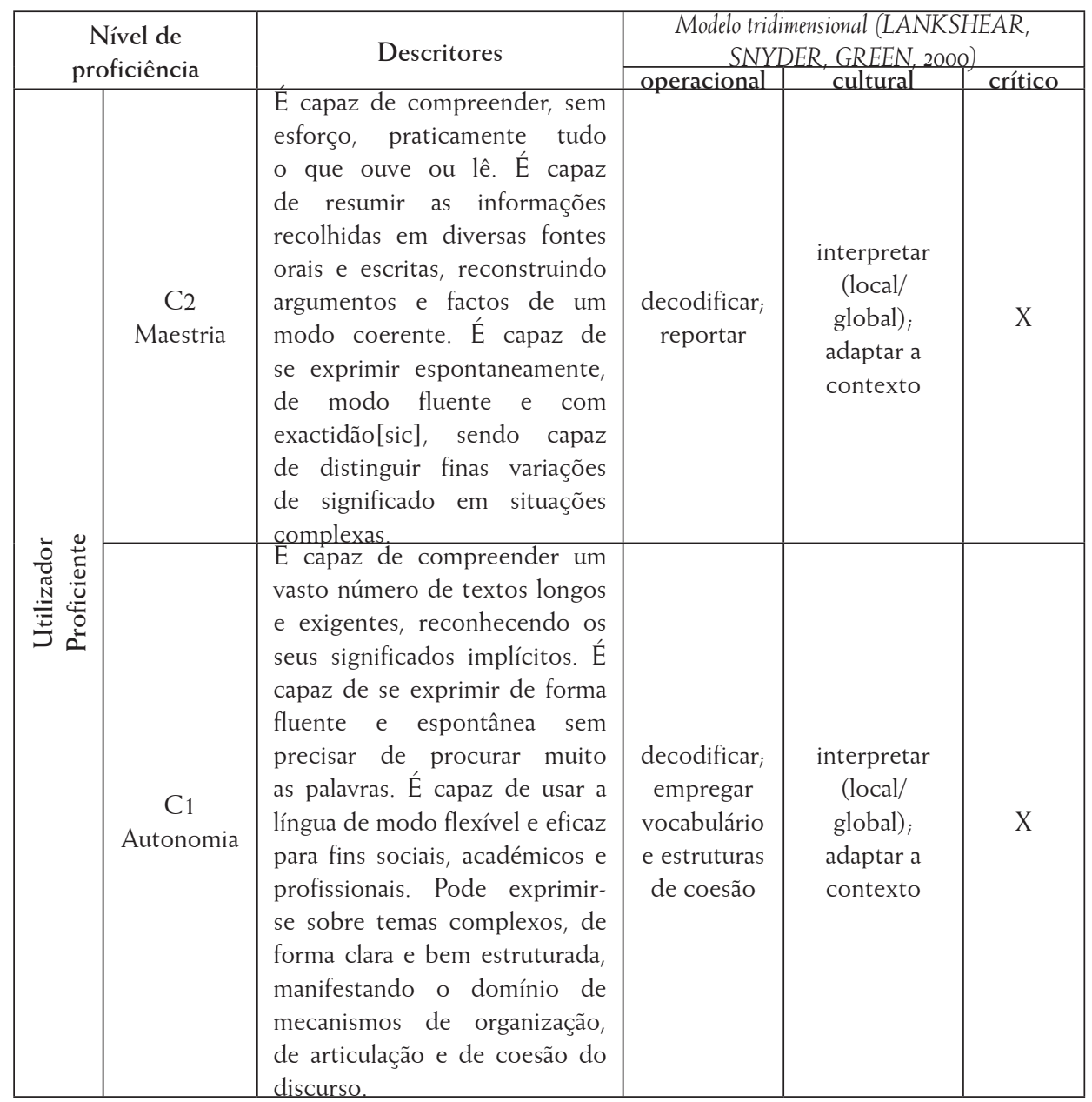




\begin{tabular}{|c|c|c|c|c|c|}
\hline \multirow{2}{*}{ 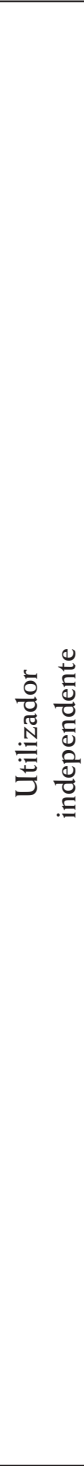 } & $\begin{array}{c}\text { B2 } \\
\text { Vantagem }\end{array}$ & $\begin{array}{l}\text { E capaz de compreender as } \\
\text { ideias principais em textos } \\
\text { complexos sobre assuntos } \\
\text { concretos e abstractos[sic], } \\
\text { incluindo discussões técnicas } \\
\text { na sua área de especialidade. É } \\
\text { capaz de comunicar-se com um } \\
\text { certo grau de espontaneidade } \\
\text { e de à-vontade com falantes } \\
\text { nativos, sem que haja tensão } \\
\text { de parte a parte. É capaz de } \\
\text { exprimir-se de modo claro } \\
\text { e pormenorizado sobre } \\
\text { uma grande variedade de } \\
\text { temas e explicar um ponto } \\
\text { de vista sobre um tema da } \\
\text { actualidade[sic], expondo as } \\
\text { vantagens e os inconvenientes } \\
\text { de várias possibilidades. }\end{array}$ & $\begin{array}{c}\text { decodificar; } \\
\text { empregar } \\
\text { vocabulário }\end{array}$ & $\begin{array}{c}\text { interpretar } \\
\text { (local/ } \\
\text { global); } \\
\text { adaptar a } \\
\text { contexto }\end{array}$ & $X$ \\
\hline & $\begin{array}{c}\text { B1 } \\
\text { Limiar }\end{array}$ & $\begin{array}{l}\text { E capaz de compreender as } \\
\text { questões principais, quando é } \\
\text { usada uma linguagem clara e } \\
\text { estandardizada e os assuntos } \\
\text { lhe são familiares (temas } \\
\text { abordados no trabalho, na } \\
\text { escola e nos momentos de } \\
\text { lazer, etc.). É capaz de lidar } \\
\text { com a maioria das situações } \\
\text { encontradas na região onde se } \\
\text { fala a língua-alvo. É capaz de } \\
\text { produzir um discurso simples e } \\
\text { coerente sobre assuntos que lhe } \\
\text { são familiares ou de interesse } \\
\text { pessoal. Pode descrever } \\
\text { experiências e eventos, sonhos, } \\
\text { esperanças e ambições, bem } \\
\text { como expor brevemente razões } \\
\text { e justificações para uma opinião } \\
\text { ou um projecto[sic]. }\end{array}$ & $\begin{array}{c}\text { decodificar; } \\
\text { empregar } \\
\text { vocabulário } \\
\text { e estruturas } \\
\text { específicas }\end{array}$ & $\begin{array}{c}\text { interpretar e } \\
\text { produzir } \\
\text { (local) }\end{array}$ & $X$ \\
\hline
\end{tabular}




\begin{tabular}{|c|c|c|c|c|c|}
\hline \multirow{2}{*}{ 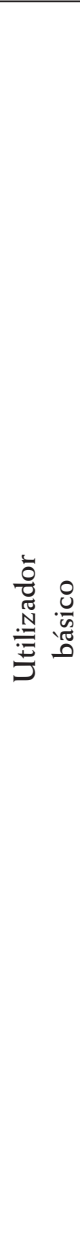 } & $\begin{array}{c}\mathrm{A} 2 \\
\text { Elementar }\end{array}$ & $\begin{array}{l}\text { E capaz de compreender } \\
\text { frases isoladas e expressões } \\
\text { frequentes relacionadas com } \\
\text { áreas de prioridade imediata } \\
\text { (p. ex.: informações pessoais } \\
\text { e familiares simples, compras, } \\
\text { meio circundante). É capaz de } \\
\text { se comunicar em tarefas simples } \\
\text { e em rotinas que exigem apenas } \\
\text { uma troca de informação } \\
\text { simples e directa[sic] sobre } \\
\text { assuntos que lhe são familiares } \\
\text { e habituais. Pode descrever de } \\
\text { modo simples a sua formação, } \\
\text { o meio circundante e, ainda, } \\
\text { referir-se assuntos relacionados } \\
\text { com necessidades imediatas. }\end{array}$ & $\begin{array}{l}\text { decodificar; } \\
\text { empregar } \\
\text { vocabulário } \\
\text { e estruturas } \\
\text { específicas }\end{array}$ & X & $X$ \\
\hline & $\begin{array}{c}\text { A1 } \\
\text { Iniciação }\end{array}$ & $\begin{array}{l}\text { E capaz de compreender e } \\
\text { usar expressões familiares } \\
\text { e quotidianas, assim como } \\
\text { enunciados muito simples, que } \\
\text { visam satisfazer necessidades } \\
\text { concretas. Pode apresentar-se e } \\
\text { apresentar outros e é capaz de } \\
\text { fazer perguntas e dar respostas } \\
\text { sobre aspectos pessoais como, } \\
\text { por exemplo, o local onde } \\
\text { vive, as pessoas que conhece } \\
\text { e as coisas que tem. Pode } \\
\text { comunicar-se de modo simples, } \\
\text { se o interlocutor falar lenta } \\
\text { e distintamente e se mostrar } \\
\text { cooperante }\end{array}$ & $\begin{array}{l}\text { decodificar; } \\
\text { empregar } \\
\text { vocabulário } \\
\text { e estruturas } \\
\text { específicas }\end{array}$ & $\mathrm{X}$ & $X$ \\
\hline
\end{tabular}

Fonte: Elaborado pelas autoras a partir QCER (CONSELHO DA EUROPA, 2001).

Nos níveis A1 e A2, são trabalhadas habilidades pertencentes ao nível operacional que, segundo Lankshear, Snyder e Green (2000), se restringem ao sistema linguístico verbal. Tal conceito poderia extrapolar o linguístico, se tivessem sido contemplados elementos multimodais (por exemplo, decodificar e produzir imagens isoladas ou em composição com outros modos) e recursos tecnológicos (buscar informações na Internet).

O conteúdo global abordado pelo QCER não explora ferramentas como a Internet que, de acordo com Mattos, é

[...] um ambiente globalizado por natureza, por ser de acesso aberto a todas as comunidades mundiais [exceto países onde governo controla e censura a rede, como a China, por exemplo], 
e também pela natureza de seu conteúdo, que não é controlado por nenhum país ou instituição especificamente (MATTOS, 2014, p. 117)

A partir do nível B1, surgem descritores que se inserem na dimensão cultural, considerando diferentes contextos sociais e suas influências na recepção e produção linguísticas. É percebido um movimento ascendente que parte do local, na forma dos contextos com os quais os utilizadores estão familiarizados para, nos níveis mais proficientes, o global, na forma do novo. Tal movimento se relaciona com o conceito de processo de design (COPE; KALANTZIS, 2000, 2009; KALANTZIS; COPE, 2012), pelo qual são apropriados os designs disponíveis, na forma do que é conhecido, para serem reconstruídos e reformulados, ao se fundirem com o que é novo, geralmente em uma atividade de produção. Os designs reformulados passam a integrar o leque de designs disponíveis, que reiniciam o ciclo.

Apesar de contemplar o movimento cíclico de construção dos significados, o QCER exclui uma condição determinante do conceito de design: a multiplicidade de recursos semióticos representados em vários modos, ou seja, a multimodalidade. Ao limitar os descritores à produção e à recepção nos modos oral e escrito, o QCER reduz o utilizador a leitor ou ouvinte, ou a falante ou escritor.

Roschel Nunes e Lorke (2011) criticam a globalização forçada do QCER, afirmando que cada indivíduo aprende de uma maneira, fator que dificulta um encaixe perfeito em um dos seis níveis descritos e aconselham o professor a refletir sobre maneiras de adaptar metas e parâmetros para sua realidade, valorizando o local. É importante ressaltar que, embora o quadro geral não apresente uma possibilidade de mobilidade entre os descritores para contemplar diferenças individuais de aprendizagem, há tentativas de incluir o local, relacionando-o ao global, ao contemplar os domínios público, privado, educativo e o profissional.

Exemplificando, descritores como o do nível B1 abrem espaço para o local e o interesse individual ao advogarem que o utilizador do idioma é

[...] capaz de produzir um discurso simples e coerente sobre assuntos que lhe são familiares ou de interesse pessoal. Pode descrever experiências e eventos, sonhos, esperanças e ambições, bem como expor brevemente razões e justificações para uma opinião ou um projecto[sic] (CONSELHO DA EUROPA, 2001, p. 49, grifos nossos).

Além disso, um dos objetivos expostos pelo QCER é manter e respeitar a diversidade linguística e cultural da Europa. Essa compreensão do outro, postulada no texto de apresentação do QCER, é parte das competências sociolinguísticas que, juntamente com as competências linguísticas e as pragmáticas, faz parte dos objetivos de aprendizagem propostos/desejados/definidos. Esse tripé pertence a 
um conjunto superior de competências comunicativas necessárias para a realização de ações (CONSELHO DA EUROPA, 2001). A visão da língua como recurso semiótico utilizado de diferentes formas em diferentes contextos sociais é adotada pela Abordagem Acional, na qual o QCER se fundamenta (id., ibid.) Apesar do atributo de agente social conferido ao utilizador na Abordagem Acional, esse não é totalmente explicitado nos descritores do QCER (ROSCHEL; NUNES, LORKE, 2011). Ele se limita a reconhecer e a respeitar as diferenças sem, todavia, problematizá-las, sob uma perspectiva mais crítica, considerando, por exemplo, questões de poder envolvendo classe social e gênero e de discurso, como proposto por Mattos e Valério (2010) e Jordão (2013).

O fato de os descritores do QCER se limitarem às dimensões operacional e cultural do letramento, não reduz seu valor; pelo contrário, essa forma de análise propulsiona uma discussão acerca das lacunas em relação à dimensão crítica, que podem ser preenchidas pelo Letramento Crítico (LC). É importante ressaltar que apesar dos hiatos encontrados nos descritores do QCER e complementados pelo LC, há pontos de interseção entre as duas abordagens como o protagonismo do aprendiz, a valorização de material autêntico, aceitação da heterogeneidade e o uso de gêneros textuais².

O objetivo deste trabalho não é analisar exaustivamente as diretrizes do QCER, mas investigar de que forma os descritores se comportam em relação às demandas de uma sociedade cuja comunicação é cada vez mais multimodal, digital e global. Além do quadro geral de referência, o documento apresenta descritores divididos por habilidade comunicativa. Serão discutidos, neste artigo, os descritores referentes aos níveis $\mathrm{C} 1$ e $\mathrm{C} 2$, pois, espera-se que utilizadores mais proficientes possuam e saibam utilizar uma considerável gama de recursos semióticos.

Em relação à produção oral, o QCER fornece uma escala de habilidades esperadas para as modalidades de produção oral geral: o monólogo em sequência descrevendo uma experiência, o monólogo em sequência argumentando, anúncios públicos e exposições públicas (Quadro 3). Mesmo com o detalhamento da habilidade comunicativa, os descritores continuam se mantendo nas dimensões operacional e cultural e apoiando-se somente na linguagem verbal presencial. Modos de produção oral, cada vez mais comuns, como as mensagens de voz de aplicativos como o Whatsapp e Skype e os vídeos postados no Facebook e Youtube são exemplos de atualizações necessárias no QCER.

2. Dentro da Abordagem Acional, os textos escritos e falados têm um objetivo social, também denominado de tarefa (JANOWSKA, 2014). 


\section{Quadro 3. Descritores da produção oral para os níveis C1 e C2}

\begin{tabular}{|c|c|c|}
\hline \multirow{2}{*}{$\begin{array}{l}\text { PRODUÇÃO ORAL } \\
\text { GERAL }\end{array}$} & $\mathrm{C} 2$ & $\begin{array}{l}\text { E capaz de produzir um discurso claro, bem estruturado, } \\
\text { fluente e com uma estrutura lógica eficaz que ajuda o } \\
\text { receptor a aperceber-se e a lembrar-se das questões mais } \\
\text { significativas. }\end{array}$ \\
\hline & $\mathrm{C} 1$ & $\begin{array}{l}\text { E capaz de fazer descrições claras e pormenorizadas e } \\
\text { de expor assuntos complexos, que integrem subtemas, } \\
\text { desenvolvendo questões específicas e terminando com uma } \\
\text { conclusão adequada. }\end{array}$ \\
\hline \multirow[b]{2}{*}{$\begin{array}{l}\text { MONÓLOGO EM } \\
\text { SEQUÊNCIA: descrever } \\
\text { uma experiência }\end{array}$} & $\mathrm{C} 2$ & $\begin{array}{l}\text { É capaz de fazer descrições elaboradas e, por vezes, } \\
\text { memoráveis, de forma clara e corrente. }\end{array}$ \\
\hline & $\mathrm{C} 1$ & $\begin{array}{l}\text { E capaz de fazer descrições de assuntos complexos, de } \\
\text { forma clara e pormenorizada. } \\
\text { É capaz de fazer descrições e narrativas elaboradas, } \\
\text { integrar subtemas, desenvolvendo questões específicas e } \\
\text { concluindo de forma apropriada. }\end{array}$ \\
\hline \multirow{2}{*}{$\begin{array}{l}\text { MONÓLOGO } \\
\text { EM SEQUÊNCIA: } \\
\text { ARGUMENTAR } \\
\text { (ex. debate) }\end{array}$} & $\mathrm{C} 2$ & Não há descritor disponível. \\
\hline & $\mathrm{C} 1$ & Não há descritor disponível. \\
\hline \multirow[b]{2}{*}{ ANÚNCIOS PÚBLICOS } & $\mathrm{C}_{2}$ & Não há descritor disponível. \\
\hline & $\mathrm{C} 1$ & $\begin{array}{l}\text { E capaz de fazer anúncios com fluência, quase sem esforço, } \\
\text { Utilizando a acentuação e a entoação para transmitir, de } \\
\text { forma precisa, diferenças mínimas de significado. }\end{array}$ \\
\hline \multirow{2}{*}{$\begin{array}{l}\text { DIRIGIR-SE A UM } \\
\text { AUDITÓRIO }\end{array}$} & $\mathrm{C} 2$ & $\begin{array}{l}\text { E capaz de expor um assunto complexo articuladamente } \\
\text { e com confiança a um auditório que com ele não está } \\
\text { familiarizado, estruturando e adaptando a exposição de } \\
\text { forma flexível para ir ao encontro das necessidades desse } \\
\text { auditório. É capaz de lidar com perguntas difíceis ou } \\
\text { mesmo hostis. }\end{array}$ \\
\hline & $\mathrm{C} 1$ & $\begin{array}{l}\text { E capaz de fazer a exposição de um assunto complexo de } \\
\text { forma clara e bem estruturada, desenvolvendo e defendendo } \\
\text { longamente pontos de vista, aduzindo informações } \\
\text { complementares, razões e exemplos pertinentes. } \\
\text { É capaz de lidar bem com as objecções do auditório, } \\
\text { respondendo espontaneamente e guase sem esforco. }\end{array}$ \\
\hline
\end{tabular}

Fonte: Adaptado de Conselho da Europa (2001)

Nas atividades de produção escrita, as escalas de habilidades englobam produção escrita geral, escrita criativa, relatórios e ensaios/composições (Quadro $4)$. 


\section{Quadro 4. Descritores da produção escrita para os níveis C1 e C2}

\begin{tabular}{|c|c|c|}
\hline & $\mathrm{C}_{2}$ & $\begin{array}{l}\text { E capaz de escrever textos complexos com clareza e fluência, } \\
\text { num estilo adequado e eficaz, com uma estrutura lógica que } \\
\text { ajuda o leitor a identificar as questões pertinentes. }\end{array}$ \\
\hline $\begin{array}{l}\text { PRODUÇÃO ESCRITA } \\
\text { GERAL }\end{array}$ & $\mathrm{C} 1$ & $\begin{array}{l}\text { E capaz de escrever textos bem estruturados, com } \\
\text { clareza, sobre assuntos complexos, sublinhando as } \\
\text { questões relevantes e mais salientes, desenvolvendo e } \\
\text { defendendo pontos de vista, acrescentando informações } \\
\text { complementares, razões e exemplos pertinentes, e } \\
\text { concluindo adequadamente. }\end{array}$ \\
\hline & $\mathrm{C}_{2}$ & $\begin{array}{l}\text { E capaz de escrever, com clareza e fluência, histórias } \\
\text { cativantes e descrições de experiências num estilo adequado } \\
\text { ao género adoptado [sic]. }\end{array}$ \\
\hline ESCRITA CRIATIVA & $\mathrm{C} 1$ & $\begin{array}{l}\text { E capaz de escrever descrições claras e pormenorizadas, } \\
\text { bem estruturadas, desenvolvidas com clareza, e textos } \\
\text { criativos num estilo seguro, pessoal, natural e adequado ao } \\
\text { leitor visado. }\end{array}$ \\
\hline \multirow{2}{*}{$\begin{array}{l}\text { RELATÓRIOS } \\
\text { E ENSAIOS/ } \\
\text { COMPOSIÇÕES }\end{array}$} & $\mathrm{C}_{2}$ & $\begin{array}{l}\text { E capaz de escrever, com clareza e fluência, relatórios } \\
\text { complexos, artigos ou composições que apresentem um } \\
\text { problema, ou apreciar criticamente propostas ou trabalhos } \\
\text { literários. } \\
\text { É capaz de fornecer uma estrutura lógica e eficaz que ajude } \\
\text { o leitor a encontrar as questões fundamentais. }\end{array}$ \\
\hline & $\mathrm{C} 1$ & $\begin{array}{l}\text { E capaz de escrever exposições claras e estruturadas, sobre } \\
\text { assuntos complexos, sublinhando as questões pertinentes e } \\
\text { salientes. } \\
\text { É capaz de desenvolver e defender pontos de vista, de } \\
\text { forma relativamente extensa, acrescentando informações } \\
\text { complementares, razões e exemplos pertinentes. }\end{array}$ \\
\hline
\end{tabular}

Fonte: Adaptado de Conselho da Europa (2001).

Movimentos localizantes e conexões globalizantes podem ser percebidos (BRANDT; CLINTON, 2002 apud MATTOS, 2014) nos descritores que, ao mesmo tempo que determinam quais normas padronizadas de gêneros textuais devem ser seguidas, incentivam a criatividade e o estilo pessoal. Apesar desse cuidado, o foco ainda é meramente descritivo e visto de um ponto, sem alusão à reflexão crítica. Por exemplo, os descritores para a escrita criativa poderiam incluir apresentar diferentes pontos de vista aos fatos narrados/descritos. Jordão (2013) assevera que para letrar criticamente não é necessário abordar somente temas polêmicos ou associados à opressão social, mas desenvolver a habilidade do múltiplo olhar que permite a leitura de um texto sob várias perspectivas, não ficando restrito a uma interpretação somente.

A produção escrita está diretamente relacionada à visão de texto que, para o QCER, é 
[...] qualquer referência discursiva, oral ou escrita, que os utilizadores/aprendentes recebem, produzem ou trocam. [...] Os textos têm muitas funções diferentes na vida social e apresentam, consequentemente, diferenças na forma e na substância. Diferentes suportes são usados com finalidades diferentes. As diferenças de suporte, de finalidade e de função conduzem a diferenças correspondentes não apenas no contexto das mensagens, mas também na sua organização e na sua apresentação. Portanto, os textos podem ser classificados em diferentes tipos, pertencendo a diferentes géneros (CONSELHO DA EUROPA, 2001, p. 136).

Apesar da incorporação da teorização de gêneros textuais, o QCER reconhece como tais somente os produzidos pela escrita ou pela fala. Mesmo quando os textos se apresentam por diferentes suportes, como voz, telefone, teleconferência, computador, TV entre outros, o QCER ignora o teor multimodal dos gêneros pelos quais interagimos. O Quadro 5 retrata como a 'diversidade' dos gêneros é abordada no documento.

Quadro 5. Tipos de gêneros textuais, segundo o QCER

\begin{tabular}{|c|c|}
\hline Oral & Escrita \\
\hline 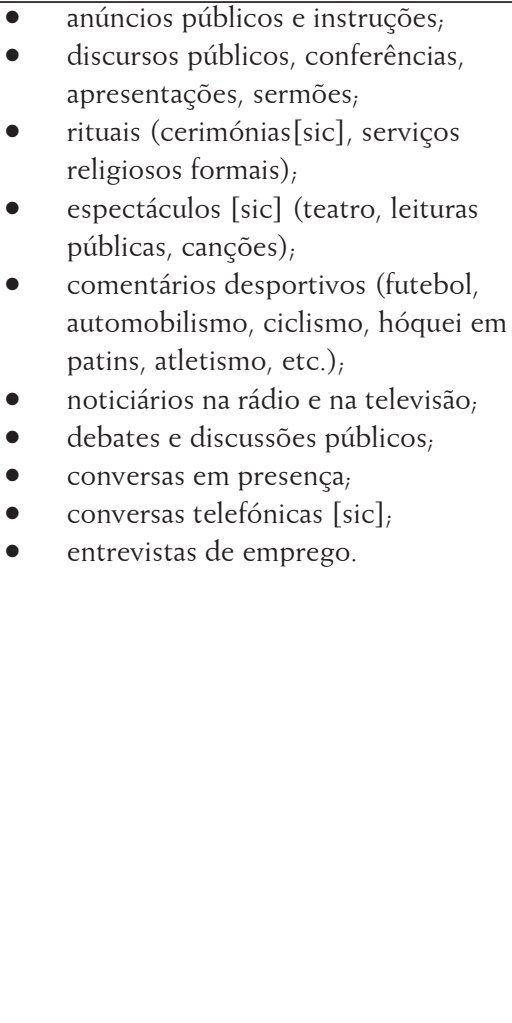 & 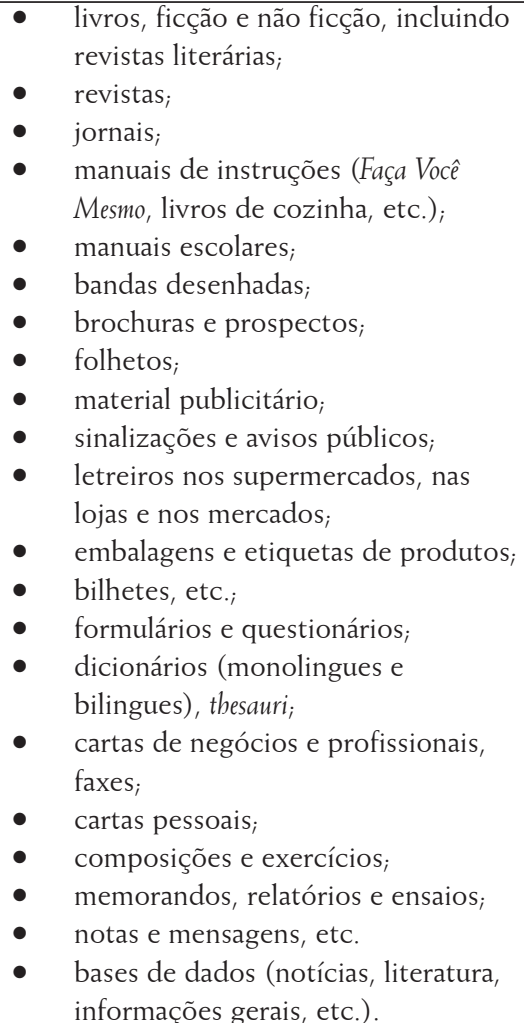 \\
\hline
\end{tabular}

Fonte: Adaptado de Conselho da Europa (2001). 
A linguagem não verbal é brevemente apresentada em duas páginas do documento, sem que haja uma problematização de seu papel na construção dos sentidos de uma composição multimodal. A apresentação se reduz a uma classificação dos elementos em gestos e ações que acompanham atividades linguísticas e que complementam seu significado, a recursos paralinguísticos, como a linguagem corporal, independente da fala: expressão facial, contato visual e físico, aos sons orais extralinguísticos, como o shbh para pedir silêncio, aos traços prosódicos como tom, volume e intensidade da voz e aos componentes paratextuais: as ilustrações, fotografias, desenhos, quadros, tabelas, esquemas, diagramas, figuras, e aspectos tipográficos.

As atividades de compreensão oral são divididas em: compreensão do oral geral, compreensão da interação entre falantes nativos, audição ao vivo como membro de um auditório, audição de anúncios e de instruções, audição de meios de comunicação áudio e de gravações (Quadro 6).

\section{Quadro 6. Descritores da compreensão oral para os níveis C1 e C2}

\begin{tabular}{|c|c|c|}
\hline \multirow[b]{2}{*}{ Compreensão do oral geral } & $\mathrm{C} 2$ & $\begin{array}{l}\text { Não tem qualquer dificuldade em compreender qualquer } \\
\text { tipo de linguagem falada, em directo [sic] ou pela rádio, } \\
\text { independentemente da sua velocidade. }\end{array}$ \\
\hline & $\mathrm{C} 1$ & $\begin{array}{l}\text { E capaz de compreender o suficiente para seguir um discurso } \\
\text { longo sobre assuntos complexos e abstractos [sic] estranhos } \\
\text { à sua área, embora necessite de confirmar pormenores } \\
\text { ocasionais, especialmente se o sotaque não lhe for familiar. } \\
\text { É capaz de reconhecer um vasto leque de expressões } \\
\text { idiomáticas e de coloquialismos, notando as mudanças de } \\
\text { registo. } \\
\text { É capaz de seguir um discurso longo, mesmo quando ele } \\
\text { não está claramente estruturado e quando as relações } \\
\text { entre as ideias se encontram implícitas e não são marcadas } \\
\text { explicitamente. }\end{array}$ \\
\hline \multirow[b]{2}{*}{$\begin{array}{l}\text { Compreensão da } \\
\text { interacção [sic] entre } \\
\text { falantes nativos }\end{array}$} & $\mathrm{C} 2$ & E capaz de seguir com facilidade interacções [sic] complexas \\
\hline & $\mathrm{C} 1$ & $\begin{array}{l}\text { entre terceiros numa discussão ou num debate de grupo, } \\
\text { mesmo sobre assuntos abstractos [sic], complexos e que } \\
\text { não lhe são familiares. }\end{array}$ \\
\hline \multirow{2}{*}{$\begin{array}{l}\text { Audição ao vivo como } \\
\text { membro de um auditório }\end{array}$} & $\mathrm{C} 2$ & $\begin{array}{l}\text { E capaz de seguir conferências e exposições especializadas } \\
\text { em que seja utilizado um grau elevado de coloquialismos, } \\
\text { usos regionais ou terminologia desconhecida. }\end{array}$ \\
\hline & $\mathrm{C} 1$ & $\begin{array}{l}\text { E capaz de seguir a maior parte das conferências, discussões } \\
\text { e debates com relativa facilidade. }\end{array}$ \\
\hline $\begin{array}{l}\text { Audição de anúncios e de } \\
\text { instruções }\end{array}$ & $\mathrm{C} 1$ & $\begin{array}{l}\text { E capaz de extrair informações específicas de anúncios } \\
\text { públicos com má qualidade sonora e acústica distorcida, p. } \\
\text { ex.: numa estação de comboios, num estádio, etc. } \\
\text { É capaz de compreender informações técnicas complexas, } \\
\text { como instruções de utilização, especificações de produtos } \\
\text { e serviços conhecidos. }\end{array}$ \\
\hline
\end{tabular}




\begin{tabular}{|c|c|l|}
\hline $\begin{array}{c}\text { Audição de meios de } \\
\text { comunicação áudio e de } \\
\text { gravações }\end{array}$ & C2 & $\begin{array}{l}\text { É capaz de entender uma ampla gama de material áudio } \\
\text { gravado ou transmitido, incluindo os usos que não são } \\
\text { padrão, e identificar minúcias, incluindo atitudes implícitas } \\
\text { e relações entre falantes. }\end{array}$ \\
\hline
\end{tabular}

Fonte: Adaptado de Conselho da Europa (2001).

Novamente, são perceptíveis os movimentos entre o local, presente nos regionalismos e discursos específicos de determinados grupos, e o global, presente nos gêneros orais. Outro fator relevante é a menção de usos não padronizados da língua, valorizando a heterogeneidade (MATTOS, VALÉRIO, 2010). Também são consideradas atitudes implícitas e relações entre falantes, contudo, não há uma explicitação das relações de poder envolvidas nem das vozes presentes nos discursos, sugerindo que a dimensão crítica do letramento (LANKSHEAR, SNYDER; GREEN, 2000) não é considerada.

As habilidades de compreensão escrita incluem: a compreensão escrita geral, a leitura de correspondência, a leitura para orientação, a leitura para obter informações e argumentos e a leitura de instruções (Quadro 7).

\section{Quadro 7. Descritores da compreensão escrita para os níveis C1 e C2}

\begin{tabular}{|c|c|c|}
\hline \multirow[t]{2}{*}{$\begin{array}{c}\text { Compreensão na leitura } \\
\text { geral }\end{array}$} & $\mathrm{C} 2$ & $\begin{array}{l}\text { É capaz de ler e de interpretar criticamente praticamente todas } \\
\text { as formas de língua escrita, incluindo uma escrita abstracta } \\
\text { [sic], estruturalmente complexa, cheia de coloquialismos, } \\
\text { literária ou não literária. } \\
\text { É capaz de entender um vasto leque de textos longos e } \\
\text { complexos, apreciando distinções de estilo subtis, significados } \\
\text { implícitos e explícitos. }\end{array}$ \\
\hline & $\mathrm{C} 1$ & $\begin{array}{l}\text { É capaz de entender em pormenor textos longos e complexos } \\
\text { relacionados ou não com a sua área de especialidade, desde } \\
\text { que possa voltar a ler as secções [sic] difíceis. }\end{array}$ \\
\hline \multirow{2}{*}{$\begin{array}{c}\text { Leitura de } \\
\text { correspondência }\end{array}$} & $\mathrm{C}_{2}$ & \multirow{2}{*}{$\begin{array}{l}\text { E capaz de entender qualquer correspondência, utilizando } \\
\text { pontualmente o dicionário. }\end{array}$} \\
\hline & C1 & \\
\hline \multirow[b]{2}{*}{ Leitura para orientação } & $\mathrm{C} 2$ & \multirow{2}{*}{$\begin{array}{l}\text { É capaz de percorrer rapidamente um texto longo e complexo, } \\
\text { localizando pormenores relevantes. } \\
\text { É capaz de identificar rapidamente o conteúdo e a relevância } \\
\text { de novas questões, artigos e relatórios acerca de um vasto } \\
\text { leque de assuntos profissionais, decidindo se vale a pena um } \\
\text { estudo mais aprofundado. }\end{array}$} \\
\hline & $\mathrm{C} 1$ & \\
\hline \multirow[b]{2}{*}{$\begin{array}{c}\text { Leitura para obter } \\
\text { informações e argumentos }\end{array}$} & $\mathrm{C}_{2}$ & \multirow{2}{*}{$\begin{array}{l}\text { E capaz de entender em pormenor um vasto leque de } \\
\text { textos longos e complexos, passíveis de ocorrerem na vida } \\
\text { social, profissional ou académica, identificando pequenos } \\
\text { pormenores que incluem atitudes e opiniões implícitas ou } \\
\text { abertamente expressas. }\end{array}$} \\
\hline & $\mathrm{C} 1$ & \\
\hline
\end{tabular}




\begin{tabular}{|c|c|l|}
\hline \multirow{2}{*}{ Leitura de instruções } & C2 & $\begin{array}{l}\text { É capaz de entender em pormenor instruções longas e } \\
\text { complexas acerca de uma nova máquina ou de um novo } \\
\text { procedimento, quer essas instruções se relacionem com a sua } \\
\text { área de especialização quer não, desde que possa voltar a ler } \\
\text { as secções [sic] mais difíceis. }\end{array}$ \\
\hline
\end{tabular}

Fonte: Adaptado de Conselho da Europa (2001) - Grifo das autoras.

Embora o termo criticamente seja mencionado em um dos descritores da compreensão escrita, no quadro anterior (em negrito), ele não traduz as condições do LC, principalmente, porque as atividades de leitura, assim como as de compreensão oral, são baseadas na extração do significado do texto e não em sua construção (JORDÃO, 2013). Outro fator negligenciado é a leitura de imagens que, segundo Kress (2003), principalmente nos textos digitais, são tão ou até mais importantes que a linguagem verbal.

O QCER faz uma tímida incursão na multimodalidade, ao acrescentar descritores para recepção de audiovisual que incluem as habilidades de: seguir um texto à medida que é lido em voz alta, ver TV, vídeo ou um filme com legendas e utilizar novas tecnologias (multimídia, CD-ROM etc. Contudo, só é fornecida uma escala para a habilidade ver TV e filmes, na qual o utilizador proficiente (C2 ou C1) "é capaz de seguir filmes que utilizem um grau considerável de calão e de expressões idiomáticas" (CONSELHO DA EUROPA, 2001, p. 110), sendo a utilização de novas tecnologias e formas de letramento emergentes (LANKSHEAR, SNYDER. GREEN, 2000) negligenciadas. Além disso, perde-se uma oportunidade de possibilitar discussões sobre o poder da mídia como disseminadora de ideologias.

\section{CONSIDERAÇÕES FINAIS}

A influência do QCER nas ações que integram o programa de internacionalização da IES demanda um olhar mais cuidadoso sobre as diretrizes e os descritores que apresenta e descreve. É importante ressaltar que o processo de internacionalização das IES brasileiras ainda apresenta pontos a serem desenvolvidos, principalmente em relação à formação do cidadão global que, além do conhecimento de mundo, possui competências interculturais e conhece sua responsabilidade social (CLIFFORD, 2016). Nesse processo, é fundamental o papel das Tecnologias Digitais de Informação e Comunicação (TIDCs), pois, ao encurtar distâncias, rompendo barreiras geográficas e temporais, permitem novas formas de internacionalização que não demandam deslocamento dos indivíduos envolvidos. 
Nesse sentido, Jorge (2016) ressalta a importância da internacionalização em casa por meio de letramentos que envolvem linguagens e aspectos culturais de outros países e preparam discentes para futuros programas de mobilidade, letramentos esses que, segundo Beelen e Jones (2015), devem ser integrados ao currículo.

Neste artigo, foram discutidos aspectos do QCER que deixam lacunas a serem preenchidas pelos Multiletramentos e pelo Letramento Crítico, mas, também, aspectos positivos do QCER como a preocupação em deixar espaço para que os contextos locais sejam contemplados nas práticas de ensino de línguas, ainda que o que é medido nos exames de proficiência possa criar um global comum e engessado. Em relação aos Multiletramentos, mesmo que haja inclusão de textos que, por sua natureza, são multimodais, QCER não ressalta tal aspecto, nem o trabalho como competência comunicativa.

Embora não tenhamos analisado os livros didáticos aprovados pelo Plano Nacional do Livro Didático (PNLD, 2017), detectamos, em seu manual de instruções, o multiletramentos, o letramento crítico e as tecnologias digitais como temas recorrentes nas coleções. Quanto aos exames de proficiência, reconhecemos serem ainda muito baseados nos textos escritos e na fala, e ainda vistos de forma não integrada. Também, é preciso integrar o quadro às tecnologias digitais, às novas formas de significação e às novas habilidades de letramento emergentes. A influência da Internet nos movimentos de localização e globalização é outro aspecto que necessita ser problematizado pelo QCER.

Para contemplar práticas de Letramento Crítico, propomos a inclusão de descritores que considerem os quatro princípios apresentados por McLaughlin e DeVoogd (2004), a saber: a) a discussão das relações de poder visando à ação transformativa; $b$ ) a problematização do contexto educacional, reconhecendo sua complexidade; c) o dinamismo e adaptabilidade aos diferentes contextos e d) a ruptura com o senso comum e a substituição de antigas práticas pedagógicas pela exploração de perspectivas múltiplas. Deve-se, portanto, ultrapassar a dimensão de reconhecimento e de aceitação de diferentes culturas e caminhar para uma análise crítica e criteriosa do contexto social, das relações de poder, da influência das tecnologias digitais nas interações e na construção do significado, das ideologias, dos papéis sociais, enfim, de todos os elementos que subjazem à opacidade dos (inter) discursos.

Salientamos que a análise apresentada neste artigo não tem a pretensão de esgotar a discussão sobre o QCER e sua influência no programa de internacionalização das IES. Outros aspectos que emergiram da análise e não foram abordados como as 
diretrizes para avaliação e autoavaliação, a formação de professores e a análise do currículo podem e devem ser explorados em trabalhos futuros.

\section{$\overline{\text { REFERÊNCIAS }}$}

BEELEN, Ji JONES, E. (2015). Redefining internationalisation at home. In: CURAJ, A.; MATEI, L.; PRICOPIE, R.; SALMI, J.; SCOTT, P. (Eds.). The European bigher education area: Between critical reflections and future policies. Dordrecht: Springer.

BRASIL. Ministério da Ciência, Tecnologia e Inovação (MCTI), Ministério da Educação (MEC), Conselho Nacional de Desenvolvimento Científico e Tecnológico (CNPq), \& Coordenação de Aperfeiçoamento de Pessoal de Nível Superior (CAPES). Programa Ciência sem Fronteiras. Decreto No 7.642 de 13 de dezembro de 2011 . Brasília, DF. Disponível em: http://isf.mec.gov.br. Acesso em: 27/05/2017.

BRASIL. Ministério da Educação. PNLD 2017: língua estrangeira moderna: espanhol e inglês. Secretaria de Educação Básica-SEB. Brasília, DF. 2016. Disponível em: http://www. fnde.gov.br/programas/livro-didatico/guias-do-pnld/item/8813-guia-pnld-2017. Acesso em: 09/06/2017.

CASTELL, S, LUKE, A.; MACLENNAN, A. (1986). On defining literacy. In: CASTELL, S. LUKE, A. \& EGAN, K. (eds.). Literacy, Society and Schooling: A reader. Cambridge: Cambridge University Press.

CLIFFORD, Valerie A. (2017). Exploring internationalization of the curriculum through the lens of global citizenship. In: LUNA, José Marcelo Freitas (org.). Internacionalização do currículo: educação- interculturalidade - cidadania global. Campinas: Pontes.

CONSELHO DA EUROPA. Quadro comum europeu de referencia para as linguas: aprendizagem, ensino, avaliação. Edição portuguesa. Porto: Edições Asa, 2001. Disponível em: http://area.dge.mec.pt/gramatica/Quadro_Europeu_total.pdf. Acesso em: 01/02/2017.

BRASIL. Quadro europen comum de referência para as línguas. 2017. Disponível em: http://www.coe. int/en/web/common-european-framework-reference-languages/. Acesso em: 09 de julho de 2017.

COPE, Bill; KALANTZIS, Mary. (2009). A grammar of multimodality. International Journal of Learning, v. 16, n. 2, pp. 361-425. 
COPE, Bill; KALANTZIS, Mary. (2000). Multiliteracies: the beginnings of an idea. In: COPE, Bill; KALANTZIS, Mary. (Eds.). Multiliteracies: Literacy learning and the design of social futures. London: Routledge.

EDUCATIONAL TESTING SERVICE. TOEFL. c2015. Disponível em: < https://www. ets.org/toefl>. Acesso em: 10/05/2017.

FERREIRO, Emília; TEBEROSKY, Ana. (1986). Psicogênese da língua escrita. Tradução de Diana Myriam Lichtenstein et al. Porto Alegre: Artes Médicas.

FREIRE, Paulo. (1974). Pedagogia do oprimido. 1.ed. Rio de Janeiro: Paz e Terra.

JORDÃO, Clarissa. (2013). Abordagem comunicativa, pedagogia crítica e letramento crítico - farinhas do mesmo sacoc In: ROCHA, Cláudia Hilsdorf; MACIEL, Ruberval Franco. Língua estrangeira e formação cidadã: por entre discursos e práticas. Campinas: Pontes.

JORGE, Míriam Lúcia dos Santos. (2016). Línguas estrangeiras em evidência: formação de professores, justiça social e letramentos. In: FERREIRA, Maria Cristina Faria Dalacorte; REICHMANN, Carla Lynn; ROMERO, Tania Regina de Souza (Orgs.). Construções Identitárias de Professores de Línguas. Campinas: Pontes.

KALANTZIS, Mary; COPE, Bill. (2012). Multiliteracies in Education. In: The Encyclopedia of Applied Linguistics: Wiley.

KRESS, Gunther. (2003). Literacy in the New Media Age. London and New York: Routledge.

LANKSHEAR, Colin; SNYDER, Ilana; GREEN, Bill. (2000). Teachers and techno literacy: managing literacy, technology and learning in schools. Sydney: Allen \& Unwin.

LANKSHEAR, Colin; KNOBEL, Michele. (2003). New literacies: changing knowledge and classroom learning. Buckingham: Open University Press.

LÉVY, Pierre. (2011). O que é o virtual? Tradução de Paulo Neves. São Paulo: Editora 34.

MATTOS, Andréa Machado de Almeida; VALÉRIO, Kátia Modesto. (2010). Letramento crítico e ensino comunicativo: lacunas e interseções. Revista Brasileira de Linguística Aplicada, v. 10, n. 1, pp. 135-158. Disponível em: http://www.scielo.br/scielo. php? script $=$ sci_abstract\&pid $=$ S1984-63982010000100008\&lng $=$ en \&nrm $=$ iso\&tl ng=en. Acesso em: 16/02/2017. 
MATTOS, Andréa Machado de Almeida; VALÉRIO, Kátia Modesto. Novos letramentos, globalização e ensino de inglês como língua estrangeira. (2014). In: ZACCHI, Vanderlei; STELLA, Paulo Rogério (Orgs.). Novos letramentos, formação de professores e ensino de língua inglesa. Maceió: Edufal.

MCLAUGHLIN, Maureen; DeVOOGD, Glenn Lawrence. (2004). Critical literacy: enhancing students' comprehension of text. New York: Scholastic.

THE NEW LONDON GROUP. A Pedagogy of Multiliteracies: designing social futures. HarvardEducationalReview, v. 66, n. 1, p.60-92, 1996. Disponívelem:http://vassarliteracy. pbworks.com/f/Pedagogy+of+Multiliteracies_New+London+Group.pdf. Acesso em: 09/06/2017.

ROSCHEL NUNES, Elaine C.; LORKE, Franzisca. (2011). O problema da adequação dos parâmetros do Quadro Europeu Comum de Referência e "a necessidade de emergir como os outros de nós mesmos". Revista X, v.2, pp. 40-60. Disponível em: http:// ojs.c3sl.ufpr.br/ojs/index.php/revistax/article/view/22892. Acesso em: 02/07/2015.

SOARES, Magda. (2009). Letramento: um tema em três gêneros. 2. ed. Belo Horizonte: Autêntica.

STREET, Brian Vincent. (1984). Literacy in theory and practice. Cambridge: Cambridge University Press.

Recebido: 1/08/2017

Aceito: 18/07/2018 